Article

\title{
Improving the Energy Concentration in Waste Printed Circuit Boards Using Gravity Separation
}

\author{
Amit Kumar ${ }^{1, *}$, Vinoth Kumar Kuppusamy ${ }^{1}$, Maria E. Holuszko ${ }^{1}$ and Travis Janke ${ }^{2}$ \\ 1 NBK Institute of Mining Engineering, University of British Columbia, Vancouver, BC V6T 1Z4, Canada; \\ vinothkumar@alumni.ubc.ca (V.K.K.); meh@apsc.ubc.ca (M.E.H.) \\ 2 Ronin8 Technologies Limited, Richmond, BC V7A 4T9, Canada; travis@ronin8.com \\ * Correspondence: amit.kumar.ism@gmail.com; Tel.: +1-604-379-9093
}

Received: 5 April 2018; Accepted: 11 May 2018; Published: 16 May 2018

\begin{abstract}
Electronic waste is one the fastest growing waste streams in the world, and printed circuit boards (PCBs) are the most valuable fraction of this stream due to the presence of gold, silver, copper, and palladium. Printed circuit boards consist of approximately $30 \%$ metals and $70 \%$ non-metals. The non-metal fraction (NMF) is composed of $60-65 \%$ fiberglass and $35-40 \%$ organics, in the form of surface-mount plastics and epoxy resins in the printed circuit board laminates. The organics in the NMF provide a potential alternative source of energy, but hazardous flame retardants contained in epoxy resins and the presence of residual metals create challenges for utilizing this material for energy recovery. This research provides an evaluation of the energy content of printed circuit boards. Density-based separation was used to separate various components of the NMF to increase the energy content in specific density fractions while reducing the metal content. The result showed that the energy content before and after the removal of the metallic fraction from PCBs was 9 and $15 \mathrm{GJ} / \mathrm{t}$, respectively. After the density-based separation of the NMF, the energy content in the lightest fraction increased to $21 \mathrm{GJ} / \mathrm{t}$, while reducing the concentration of the hazardous flame retardants. The contents of the hazardous flame retardants and residual metal were analyzed, to evaluate the harmful effect of emissions produced from utilizing the NMF as an alternative feedstock in waste-to-energy applications.
\end{abstract}

Keywords: e-waste; printed circuit boards; resins; fiberglass; calorific value; energy recovery

\section{Introduction}

Electrical and electronic products have become an integral part of today's lifestyle. With the development of newer and faster technologies, the older products are becoming obsolete at an ever-growing rate. E-waste, the term used for the discarded electrical and electronic products, is one of the fastest growing waste streams in the world, with an approximate growth rate of 3-4\% [1]. The total e-waste generated in 2016 was estimated at 45 million tons [1]. The e-waste stream has been researched in detail in the past few decades, due to the presence of valuable metals, which provides an economic incentive for extraction.

The waste printed circuit boards (PCB) represent approximately $40 \%$ of the total value of e-waste, and $6 \%$ by weight of total volume [2,3]. The average metal content of e-waste is $30-35 \%$; the rest is the non-metal fraction, which primarily contains different types of reinforcement materials and resins, depending on the type of the boards. Flame retardant (FR) boards, especially FR-2 and FR-4, are the two most common board types used in different types of electronic products such as desktops, laptops, televisions, radios, and printers. The nonmetal fraction (NMF) in a circuit board matrix is approximately $70 \%$ by mass, and consists mainly of the fiberglass (65\%), resins (32\%), and residual 
metals [4-6]. It has shown that resin concentration is highest in the coarser fractions, while fiberglass and metal content is higher in the finer size fractions of the NMF [4].

Using heavy liquids of the specific gravity of 2.89 , the metal fraction was separated and the calorific value of the nonmetal fraction was estimated to be $11.63 \mathrm{GJ} / \mathrm{t}$ [7]. Researchers have shown the application of gravity separation and flotation to separate metals from nonmetals with high efficiency $[5,8,9]$. However, research on the processing of NMF is limited. According to the United States Environmental Protection Agency (EPA), 94\% of the NMF materials are disposed of in landfills [10]. Researchers have proposed the use of NMFs as secondary materials in construction, paints, and adhesives or chemically convert the polymers into chemical feedstocks or fuel $[11,12]$. Triboelectric separation was used to separate the inorganic fiberglass from the NMF to improve the product quality, achieving a $43 \%$ recovery rate [13].

This paper considers the separation of various components of the nonmetal fraction (resins, fiberglass, and residual metals) to increase the energy content of the waste PCBs. Heavy liquids of varying densities $\left(1.6,1.8\right.$ and $\left.2.4 \mathrm{~g} / \mathrm{cm}^{3}\right)$ were used for this purpose, and the separated components were analyzed for metal content and calorific value. The products were also analyzed for harmful flame retardants that would be released during the energy recovery process.

\section{Materials and Methods}

\subsection{Material}

Approximately $25 \mathrm{~kg}$ of representative shredded PCB feed and gravity separation tailings (NMF) was sampled from a processing plant located in Richmond, British Columbia, owned by Ronin8 Technologies Limited. The plant processes a mixture of FR-2 and FR-4 PCBs obtained from computers, printers, televisions, servers, cellphones, and other household electronics. The crushed PCBs are processed using gravity separation to separate metals from non-metals. The sample was oven dried at $60{ }^{\circ} \mathrm{C}$ for $96 \mathrm{~h}$ to remove residual moisture.

\subsection{Equipment and Test Procedures}

\subsubsection{Calorific Value Measurement}

Approximately 5 grams of subsamples was obtained for the calorific value measurement and was performed using a Parr 6100 Calorimeter and a Parr 4510 nickel alloy wire following American Society for Testing and Materials (ASTM, West Conshohocken, PA, USA) D5965 guidelines.

\subsubsection{Float-Sink Test}

The float and sink test was carried out to access the feasibility of using dense media as a separation technology to separate various streams of the NMF. Organic liquids of specific gravities (SG) 1.6, 1.8 and 2.4 were prepared by mixing tetra bromoethane (SG 2.95) and kerosene (SG 0.8). The liquids were used to perform the float-sink test on $+500 \mu \mathrm{m}$ and $-500+75 \mu \mathrm{m}$ size fraction. The separated components were then used for subsequent analysis.

To perform the float and sink test, the sample was placed in the heavy liquid with the lowest specific gravity, mixed, and allowed to settle. Floating particles were collected with a fine mesh scoop that allowed excess liquid to drain. Each heavy liquid vessel contained an "inner beaker" with a fine mesh bottom for collecting the sinking fraction. After removing all the floating particles, the inner vessel with the sink material was removed and transferred to the next heavy liquid. Any particles floating on this liquid were lighter than the previous liquid, but heavier than the current liquid. All the separated fractions were collected and washed with acetone, filtered, dried, weighed and analyzed. 


\subsubsection{Metal Assay}

Approximately 20 grams of subsample was split using a riffle splitter, and was sent to an external laboratory for metal assay using standard procedures provided by the Environmental Protection Agency: EPA200.2/6020A for metals and EPA200.2/1631E for mercury. This procedure is designed to determine the total recoverable elements in water and solids, with the exception of silica [14].

\subsubsection{Polybrominated Diphenyl Ether (PBDE) Analysis}

PBDE is a set of organic compounds that are commonly added to the electronic castings as flame retardants [15]. There are many congeners for this compound depending on the number of bromine atoms, and their location. Approximately 20 grams of samples were obtained from various density fractions and sent to the external laboratory for PBDE analysis. The extraction was performed using standard procedure EPA 3541, followed by analysis using EPA 8270D.

\section{Results and Discussion}

To evaluate the energy content of the waste $\mathrm{PCB}$, the crushed $\mathrm{PCB}$, and the nonmetal fraction samples, as received from the processing plant, were sent to ALS laboratories for calorific value measurement. The metal concentrate samples were not analyzed due to the presence of various metals which could melt and damage the analytical equipment. The results obtained from the test are shown in Table 1.

Table 1. Calorific value for shredded PCB and nonmetal fraction.

\begin{tabular}{ccccc}
\hline Sample Type & Calorific Value, (GJ/t) & Total Carbon, $\%$ & Nitrogen, $\%$ & Hydrogen, $\%$ \\
\hline Shredded PCB & 9.17 & 18.46 & 0.53 & 1.89 \\
Nonmetal fraction & 15.31 & 37.75 & 1.22 & 4.07 \\
\hline
\end{tabular}

The results showed that removal of the metals from the crushed PCB increases the energy concentration in the tailings (NMF) by $66 \%$. The total carbon, nitrogen, and hydrogen content also increased during the beneficiation process. To further improve the energy content of NMF, gravity separation was performed. The size ranges for this test were determined based on the particle size distribution of the received sample.

The particle size distribution of the received sample showed that approximately $50 \%$ of materials was less than $500 \mu \mathrm{m}$. Since almost half of the material was passing through $500 \mu \mathrm{m}$, all the tests were performed on $+500 \mu \mathrm{m}$ and $-500+75 \mu \mathrm{m}$. The sample below $75 \mu \mathrm{m}$ was considered as too small for the float and sink test.

The float and sink tests were carried out at 1.6, 1.8, and 2.4 specific gravities, for $+500 \mu \mathrm{m}$ (coarse) and $-500+75 \mu \mathrm{m}$ (fine). The percentage yield for the products obtained from the float-sink test on coarse and fine samples are shown in Figure 1. The results showed that approximately $60-70 \%$ of the materials in the non-metal fractions are in the $-1.8 \mathrm{SG}$, whereas a very small amount of the samples is present in the heaviest fraction (+2.4 SG), which suggests that most of the heavy metals were recovered during the beneficiation stage in the processing plant (' $+500^{\prime}$ represents material coarser than $500 \mu \mathrm{m}$ whereas ' -75 ' represents material finer than $75 \mu \mathrm{m}$ ).

The calorific value of each density fraction was determined to estimate the energy value of different products. The results for the calorific values are shown in Figure 2. The red line represents the calorific value of the NMF as received, whereas the green line represents the calorific value of the shredded waste PCB prior to any separation. The heaviest fraction $(+2.4 \mathrm{SG})$ of $+500 \mu \mathrm{m}$ was not tested, due to the presence of metal strands that could damage the analytical instrument. The results showed that the calorific value in the lower density fractions was increased to $21 \mathrm{GJ} / \mathrm{t}$, compared to $15 \mathrm{GJ} / \mathrm{t}$ for the whole nonmetal fraction. This is most likely due to a higher concentration of the epoxy 
resins in the low-density fractions. Energy concentration in the higher density fraction decreased to below $10 \mathrm{GJ} / \mathrm{t}$, due to the removal of most of the resin materials.

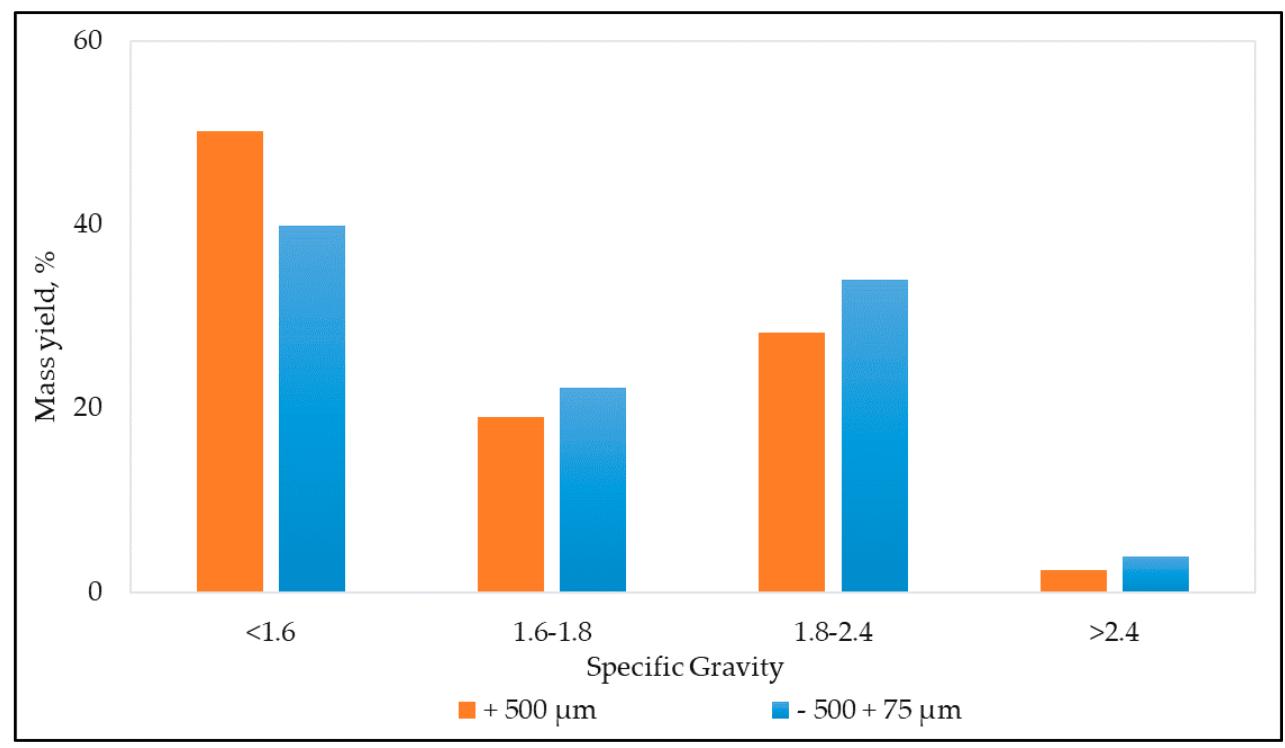

Figure 1. Yield of different specific gravities products for coarse and fine samples.

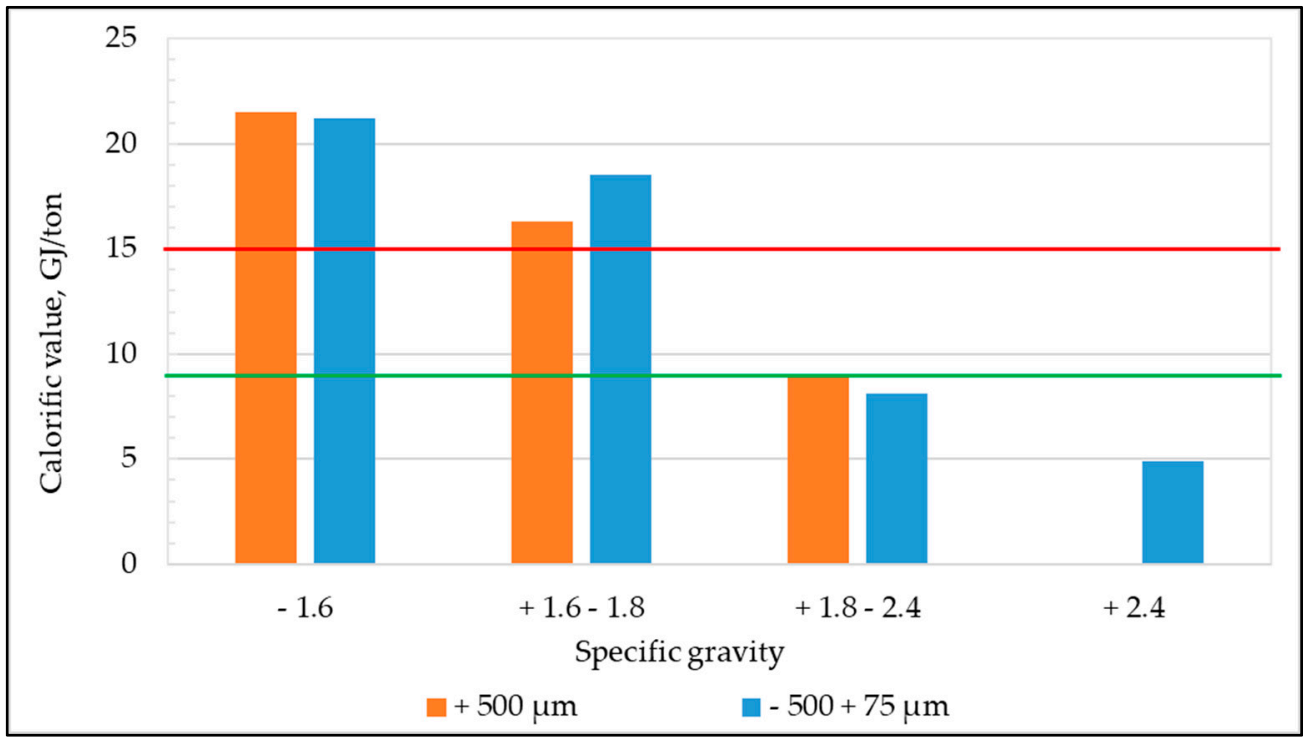

Figure 2. Calorific value of different SG fractions for the coarse and fine sample.

Table 2 shows the change in the calorific value of various density fractions obtained from the float and sink test, compared to the NMF as received. It shows that the energy content in the lighter fraction was increased by approximately $40 \%$, whereas it was decreased by $68 \%$ in the heaviest fraction. This suggests that gravity separation can be used for improving the calorific value of the NMF.

The metal content analysis of each specific gravity fraction for coarse and fine sizes was performed to determine the concentration of heavy metals in different size fractions. The results of the metal content analysis can be seen in Figure 3. Only significant metal concentration results $(>0.5 \%)$ are shown in Figure 3. The metal content for almost all heavy elements is highest in the heaviest specific gravity fraction (+2.4 SG). It shows that the heavy metals should be removed if the NMF is treated to improve the energy content, as the lightest fraction has the highest energy content and negligible metal content. 
It also suggests that the process will be a potential opportunity for removing hazardous heavy metals prior to incineration.

Table 2. Percentage change in the calorific value of various destiny fractions compared to the NMF.

\begin{tabular}{ccc}
\hline Specific Gravity & $\mathbf{+ 5 0 0 \mu \mathrm { m }}$ & $\mathbf{- 5 0 0 + 7 5 \mu \mathrm { m }}$ \\
\hline$<1.6$ & $+41 \%$ & $+39 \%$ \\
$1.6-1.8$ & $+7 \%$ & $+21 \%$ \\
$1.8-2.4$ & $-42 \%$ & $-47 \%$ \\
$>2.4$ & - & $-68 \%$ \\
\hline
\end{tabular}
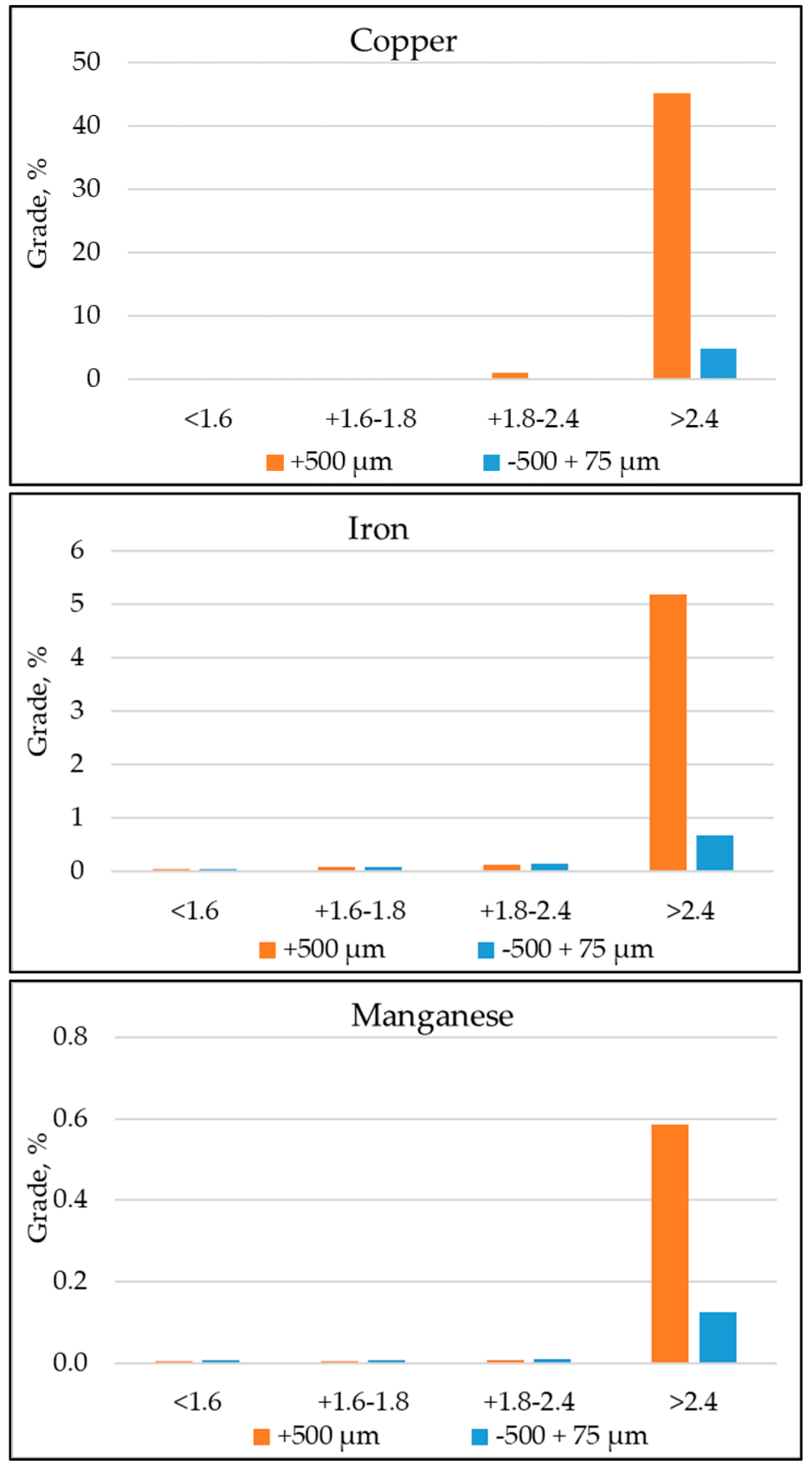

Figure 3. Cont. 


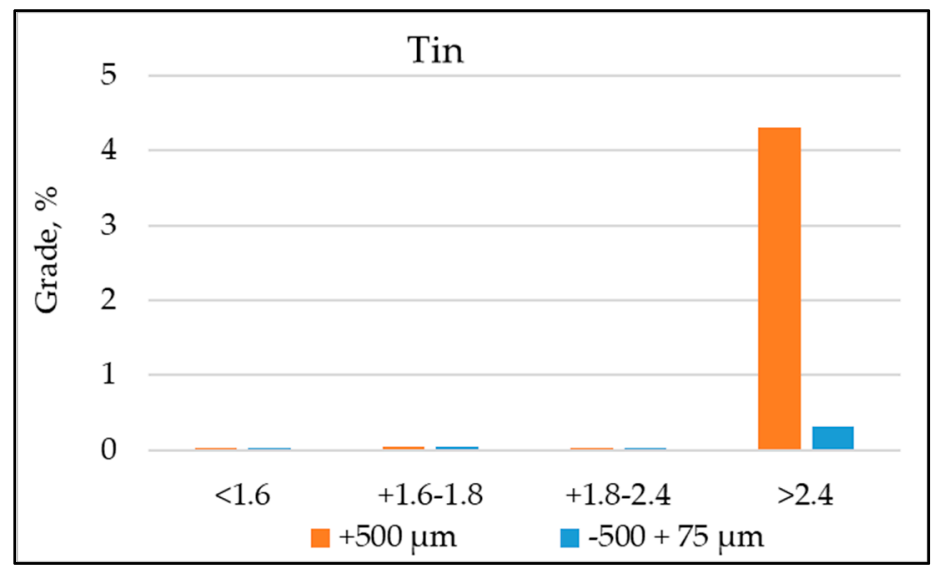

Figure 3. Metal content in different specific gravity fraction of the coarse and fine sample.

Some of the harmful chemicals present in PCBs are the flame retardants which are added to the laminate matrix to suppress the spontaneous ignition of the materials. One of the most common flame retardants is polybrominated diphenyl ether (PBDE), which belongs to a family of different congeners. The nonmetal fraction with high energy content, -1.6 SG fraction and +1.6-1.8 SG fractions, were analyzed for the presence of the PBDEs. The PBDE can be released into the environment through emissions, volatilization, incineration, or thermal decomposition of the PCB waste, and can be exposed to humans through ingestion, inhalation, and dermal contact $[15,16]$. The result for the PBDE content for different congeners is shown in Table 3.

Table 3. Concentration of various congeners of PBDE in analyzed samples in $\mathrm{mg} / \mathrm{kg}$.

\begin{tabular}{cccccc}
\hline \multirow{2}{*}{ Analyte Name } & Nonmetal Fraction & \multicolumn{2}{c}{$\mathbf{+ 5 0 0} \boldsymbol{\mu m}$} & \multicolumn{2}{c}{$\mathbf{5 0 0 + 7 5} \boldsymbol{\mu m}$} \\
\cline { 3 - 5 } & & $\mathbf{- 1 . 6} \mathbf{~ S G}$ & $\mathbf{+ 1 . 6 - 1 . 8 ~ S G}$ & $\mathbf{- 1 . 6 ~ S G}$ & $\mathbf{+ 1 . 6 - 1 . 8 ~ S G}$ \\
\hline PBDE 17 & 6.4 & 5.9 & 1.7 & 3.0 & 1.3 \\
PBDE 28 & 9.2 & 8.7 & 2.6 & 4.3 & 1.8 \\
PBDE 71 & 1.7 & 1.0 & 0.2 & 0.4 & 0.2 \\
PBDE 47 & 52.0 & 54.0 & 14.0 & 27.0 & 12.0 \\
PBDE 66 & 18.0 & 17.0 & 4.9 & 8.8 & 3.6 \\
PBDE 100 & 3.8 & 4.5 & 1.1 & 2.1 & 0.8 \\
PBDE 99 & 48.0 & 57.0 & 15.0 & 26.0 & 12.0 \\
PBDE 85 & 3.0 & 3.3 & 0.9 & 0.1 & 0.7 \\
PBDE 154 & 2.9 & 11.0 & 1.0 & 1.5 & 0.7 \\
PBDE 153 & 12.0 & 1.4 & 0.4 & 5.9 & 2.5 \\
PBDE 138 & 1.4 & 0.0 & 0.0 & 0.7 & 0.3 \\
PBDE 128 & 0.1 & 1.1 & 1.4 & 0.0 & 0.0 \\
PBDE 183 & 5.5 & 0.1 & 0.0 & 0.8 & 0.6 \\
PBDE 190 & 0.2 & 0.2 & 0.3 & 0.0 & 0.0 \\
PBDE 203 & 0.7 & 5.4 & 6.3 & 0.2 & 0.1 \\
PBDE 206 & 9.0 & 60.0 & 82.0 & 150.0 & 61.0 \\
PBDE 209 & 120.0 & $\mathbf{2 3 3 . 8}$ & $\mathbf{1 3 5 . 2}$ & $\mathbf{2 3 7 . 3}$ & $\mathbf{1 0 2 . 0}$ \\
\hline Total & $\mathbf{2 9 3 . 9}$ & &
\end{tabular}

Figure 4 shows that the concentration of the total PBDE content in all the low-density product that will most likely be used for energy recovery purposes has decreased, compared to the NMF. The total concentration of the PBDE has been reduced by $20 \%$ for -1.6 SG fraction and by 55-65\% for +1.6-1.8 SG fraction. Most of the flame retardants might be associated with the fiberglass and metals, and hence are found in the lower density fraction. 


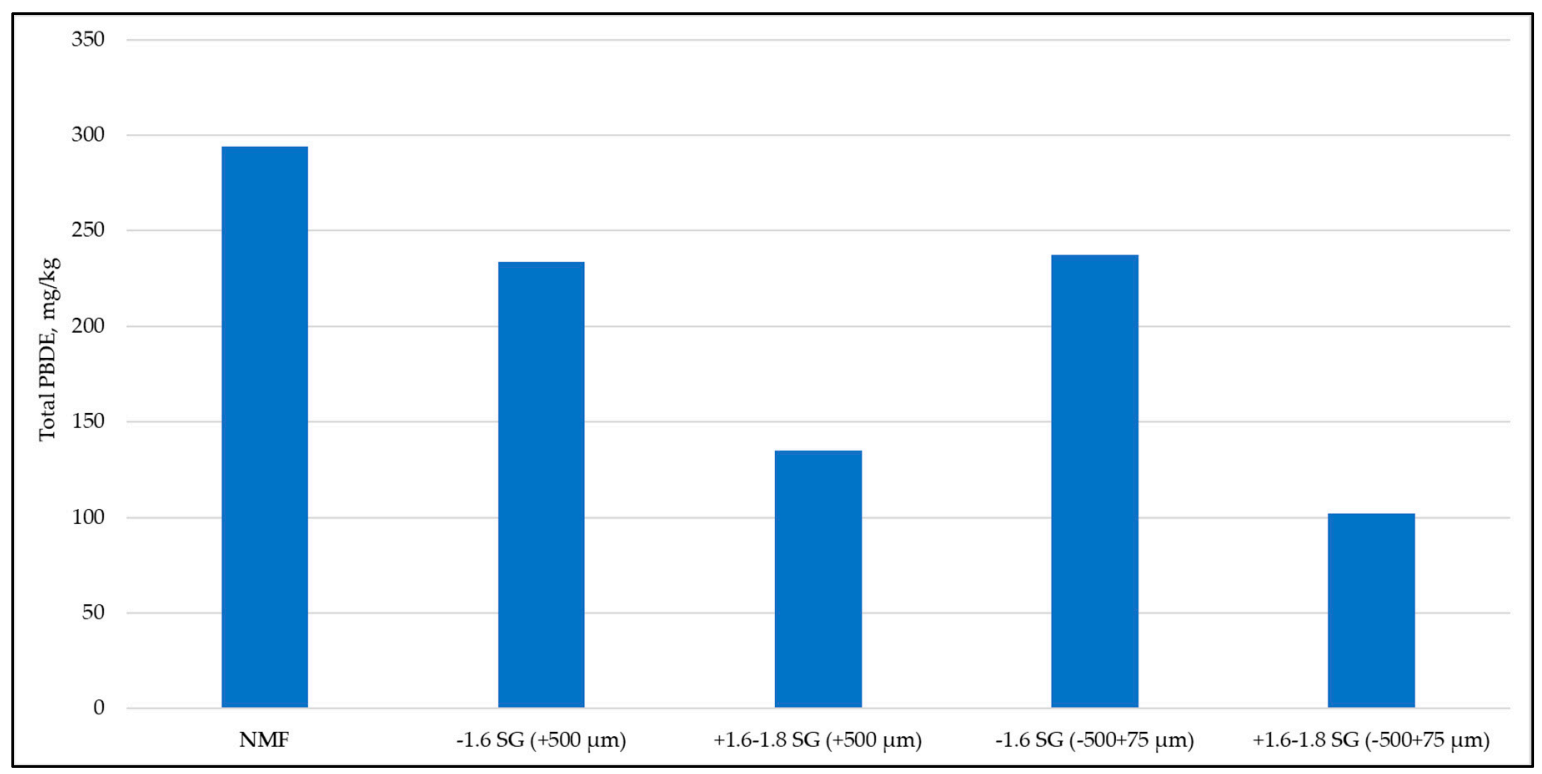

Figure 4. Change in the PBDE concertation in various density fractions.

\section{Conclusions}

The waste PCB and their various components were analyzed for their energy concentration. The results showed that the presence of the resins in the PCBs provide a good source of energy. After the removal of metals by gravity separation, and after obtaining the lighter fraction from the float-sink test, the energy content of the PCB increases from $9.17 \mathrm{GJ} / \mathrm{t}$ to $\sim 21 \mathrm{GJ} / \mathrm{t}$, which is comparable to dried wood, peat, and lignite coal. It also removes the harmful heavy metals during the process, and could provide an additional commodity in metal recovery in the +2.4 SG fraction. The process also decreases the concentration of hazardous flame retardants. However, the byproducts of the energy recovery process/incineration, such as the flue gas and fly ash, should be researched for proper disposal.

Author Contributions: This paper has been written by A.K. as his Ph.D. research with the help of V.K.K. The supervision and revision work was performed by M.E.H. and T.J.

Acknowledgments: The author acknowledges Ronin8 Technologies Limited (Richmond, British Columbia) for their financial support as well as for providing samples, expert advice, and other necessary technical details. The author also acknowledges the Canadian funding agency MITACS Inc. for their financial assistance and ALS Environmental (Burnaby, British Columbia) for performing the external laboratory analysis.

Conflicts of Interest: The authors declare no conflict of interest.

\section{References}

1. Baldé, C.P.; Forti, V.; Gray, V.; Kuehr, R.; Stegmann, P. The Global E-Waste Monitor; UNU-IAS: Bonn, Germany, 2017.

2. Evangelopoulos, P.; Kantarelis, E.; Yang, W. Investigation of the thermal decomposition of printed circuit boards (PCBs) via thermogravimetric analysis (TGA) and analytical pyrolysis (Py-GC/MS). J. Anal. Appl. Pyrolysis 2015, 115, 337-343. [CrossRef]

3. Golev, A.; Schmeda-Lopez, D.R.; Smart, S.K.; Corder, G.D.; McFarland, E.W. Where next on e-waste in Australia? Waste Manag. 2016, 58, 348-358. [CrossRef] [PubMed]

4. Marques, A.C.; Cabrera Marrero, J.-M.; de Fraga Malfatti, C. A review of the recycling of non-metallic fractions of printed circuit boards. Springerplus 2013, 2, 521. [CrossRef] [PubMed]

5. Veit, H.M.; de Freitas Juchneski, N.C.; Scherer, J. Use of gravity separation in metals concentration from printed circuit board scraps. Rem Rev. Esc. Minas 2014, 67, 73-79. [CrossRef]

6. Zheng, Y.; Shen, Z.; Ma, S.; Cai, C.; Zhao, X.; Xing, Y. A novel approach to recycling of glass fibers from nonmetal materials of waste printed circuit boards. J. Hazard. Mater. 2009, 170, 978-982. [CrossRef] [PubMed] 
7. Bizzo, W.; Figueiredo, R.; de Andrade, V. Characterization of Printed Circuit Boards for Metal and Energy Recovery after Milling and Mechanical Separation. Materials 2014, 7, 4555-4566. [CrossRef] [PubMed]

8. Das, A.; Vidyadhar, A.; Mehrotra, S.P. A novel flowsheet for the recovery of metal values from waste printed circuit boards. Resour. Conserv. Recycl. 2009, 53, 464-469. [CrossRef]

9. Duan, C.; Wen, X.; Shi, C.; Zhao, Y.; Wen, B.; He, Y. Recovery of metals from waste printed circuit boards by a mechanical method using a water medium. J. Hazard. Mater. 2009, 166, 478-482. [CrossRef] [PubMed]

10. EPA. Printed Circuit Board Recycling Methods [WWW Document]. 2012. Available online: https: / / www.epa.gov/sites/production/files/2014-05/documents/handout-10-circuitboards.pdf (accessed on 16 August 2011).

11. Guo, J.; Guo, J.; Xu, Z. Recycling of non-metallic fractions from waste printed circuit boards: A review. J. Hazard. Mater. 2009, 168, 567-590. [CrossRef] [PubMed]

12. Sohaili, J.; Muniyandi, S.K.; Mohamad, S.S. A review on printed circuit boards waste recycling technologies and reusing of recovered nonmetallic materials. Int. J. Sci. Eng. Res. 2012, 3, 138-144.

13. Zhang, G.; Wang, H.; He, Y.; Yang, X.; Peng, Z.; Zhang, T.; Wang, S. Triboelectric separation technology for removing inorganics from non-metallic fraction of waste printed circuit boards: Influence of size fraction and process optimization. Waste Manag. 2017, 60, 42-49. [CrossRef] [PubMed]

14. EPA. Method 200.2, Revision 2.8: Sample Preparation Procedure for Spectrochemical Determination of Total Recoverable Elements [WWW Document]. 1994. Available online: https:/ /www.epa.gov/sites/production/ files/2015-08/documents/method_200-2_rev_2-8_1994.pdf (accessed on 22 September 2017).

15. Guo, J.; Zhang, R.; Xu, Z. Polybrominated Diphenyl Ethers (PBDEs) Emitted from Heating Machine for Waste Printed Wiring Boards Disassembling. Procedia Environ. Sci. 2016, 31, 849-854. [CrossRef]

16. EPA. Technical Fact Sheet-Polybrominated Diphenyl Ethers (PBDEs) and Polybrominated Biphenyls (PBBs) [WWW Document]. 2014. Available online: https://www.epa.gov/sites/production/files/2014-03/ documents/ffrrofactsheet_contaminant_perchlorate_january2014_final_0.pdf (accessed on 16 August 2011).

(C) 2018 by the authors. Licensee MDPI, Basel, Switzerland. This article is an open access article distributed under the terms and conditions of the Creative Commons Attribution (CC BY) license (http:/ / creativecommons.org/licenses/by/4.0/). 